CaHIERs de Recherche / Working PAPERS

\title{
02-11
}

\section{Poverty-efficient transfer}

\author{
programs: the role of
}

\section{targeting and allocation rules}

\author{
Jean-Yves DUCLOS \\ et \\ Paul MAKDISSI \\ et \\ Quentin WODON
}

UNIVERSITÉ DE SHERBROOKE

Faculté des lettres et sciences humaines

Département d'économique 
CaHIERs de Recherche / Working PAPERS

\title{
02-11
}

\section{Poverty-efficient transfer}

\author{
programs: the role of
}

\section{targeting and allocation rules}

\author{
Jean-Yves DUCLOS \\ et \\ Paul MAKDISSI \\ et \\ Quentin WODON
}

UNIVERSITÉ DE SHERBROOKE

Faculté des lettres et sciences humaines

Département d'économique 


\title{
Poverty-efficient transfer programs: the role of targeting and allocation rules*
}

\author{
Jean-Yves Duclos ${ }^{\dagger}$ Paul Makdissi ${ }^{\ddagger}$ and Quentin Wodon ${ }^{\S}$ \\ May 2002
}

\begin{abstract}
We propose simple graphical methods to identify poverty-reducing transfer program reforms. The methods are based on Program Dominance curves that display cumulative program benefits weighted by powers of poverty gaps. These curves can be decomposed simply as sums of targeting dominance curves and allocation dominance ones, and can serve to verify whether the assessment of program reforms is sensitive to the choice of poverty lines and poverty measures as well as to differences in revenue sources and behavioral impacts across programs.
\end{abstract}

Keywords: Poverty, Targeting, Public Policy, Stochastic Dominance JEL Numbers: D31, D63,H22, H53, I32, I38

* This paper was funded through the World Bank Research Support Budget under the research project "The impact of changes in prices, taxes, subsidies and stipends on poverty when households differ in needs" and has also benefitted from the support of SSHRC, FQRSC, the MIMAP program of IDRC and the Bureau de la recherche of Universite de Sherbrooke.

† CIRPÉE, Université Laval, Québec. Corresponding address: CIRPÉE, Département d'économique, Pavillon De Sève, Université Laval, Sainte-Foy, Québec, Canada, G1K 7P4. Tel.: (418) 656-7096. Fax: (418) 656-7798. Email: jyves@ecn.ulaval.ca

‡ Département d'économique and CEREF, Université de Sherbrooke, 2550 boulevard de l'Université, Sherbrooke, Québec, Canada, J1K 2R1; email: paul.makdissi@courrier.usherb.ca

$\S$ LCSPR, World Bank, 1818 H Street, NW, Washington, DC 20433, USA, Email: qwodon@worldbank.org. 


\section{Introduction}

Governments in developed and developing countries try helping the poor in many different ways. Traditional poverty alleviation programs include inter alia consumption subsidies (for example, on food, public utilities or transportation) and low-wage public works or other forms of relief for the unemployed. In Latin America and other regions, more recent "smart" transfers include stipends for poor children conditional on school attendance (e.g., Skoufias, 2001). These transfers are said to be smart because, beyond their immediate impact on poverty, they are supposed to help achieve long-term poverty reduction through a positive impact on human capital (by the conditionality component). Even programs which are not explicitly designed to alleviate poverty may have significant impacts on the poor, and should therefore be taken into account in an overall poverty reduction strategy.

To estimate the impact of those various programs on poverty and to suggest reforms to them, analysts often resort to a comparison of some summary poverty measures with and without the programs. This technique is known to suffer from several weaknesses. One such weakness arises from a reliance on some peculiar poverty measures and from a dependence on a few selected poverty lines to estimate the poverty measures (for a general discussion of the difficulties that this can cause, see Atkinson (1987), Foster and Shorrocks (1988a, b and c), Jenkins and Lambert (1997), and Zheng (1999, 2000), among many others).

Another difficulty comes from the differential impact on tax revenues and average deadweight losses of changes in programs. If the various poverty programs are funded through the same source of government revenue, differential deadweight losses coming from the use of differential sources of revenue generation will not be an issue. However, if the programs are funded from different sources of revenues, then differences in the marginal cost of public funds that arise from differences in those revenue sources must be taken into account, and this may affect the overall poverty efficiency of program reforms (see for instance Slemrod and Yitzhaki (1996)). Yet another difficulty arises from the need to take into account the differential behavioral changes that different program reforms can generate among program beneficiaries.

An alternative avenue to the assessment of program impact consists in the analysis of targeting and of its associated "errors". This has been the 
focus of much work in recent years. ${ }^{1}$. The estimation and the interpretation of the targeting errors (variably called "leakage" and "undercoverage" errors, "E" and "F" mistakes, "Type I" and "Type II" errors) are nevertheless open to the same criticism as the above-mentioned method. The size of targeting errors can be highly sensitive to the choice of a poverty line. Their interpretation also depends strongly on particular value judgements (not always made explicit) regarding the social welfare objectives of the government - for instance, that the government cares equally for all poor, regardless of how far from the poverty line they may be. Through their use of sharp 0/1 indicators, targeting errors also tend to differentiate (too) drastically between the poor and the non poor, in particular between those in similar circumstances but who just happen to lie on opposite sides of a poverty line.

The tools developed in this paper can help alleviate most of the above concerns. More precisely, the paper builds on the stochastic dominance literature and proposes simple graphical methods for analyzing program reforms that can make the assessment of such reforms robust to the choice of poverty lines and poverty measures as well as to differences in revenue sources and behavioral impacts across program reforms. Program reforms that decrease poverty "robustly" will be called "poverty efficient". The graphical methods are based on Program Dominance $(P D)$ curves. $P D$ curves are analogous to the Consumption Dominance curves proposed by Makdissi and Wodon (2002) and Duclos, Makdissi and Wodon (2002) for the analysis of indirect tax reforms.

First-order $P D$ curves simply show the share in total program benefits of those individuals at a given income level. Second-order $P D$ curves indicate the cumulative share of total program benefits of those with income below a given threshold. Higher-order $P D$ curves weight program benefits by increasingly higher powers of poverty gaps. Increasing expenditures on program $k$ and decreasing expenditures on program $l$ is poverty efficient for all poverty lines up to some $z^{+}$and for all poverty indices of a given ethical order if the $P D$ curve of that order for program $k$ is higher than the $P D$ curve for program $l$ at every threshold under $z^{+}$.

A useful contribution of the paper consists in decomposing the $P D$ curve of any given program into targeting and allocation components. As recently noted by Coady and Skoufias (2001) and Wodon and Yitzhaki (2002) in the

\footnotetext{
${ }^{1}$ See for instance Baker and Grosch (1994), Cornia and Stewart (1995), Ravallion and Datt (1995), Grosch (1995), and Wodon (1997)
} 
context of social welfare and inequality analysis respectively, a program's "good" impact can be due to good targeting ( i.e., the poor are more likely to benefit than the non-poor), as well as to a good allocation of benefits among program participants (poorer individuals among participants receive larger benefits) - or both. We show that a $P D$ curve can be decomposed simply into the sum of a targeting dominance (TD) curve - which only takes into account who benefits or not from the program - and an allocation dominance $(A D)$ curve - which captures differences in benefit allocations among program beneficiaries.

While examination of $P D$ curves may suggest that one program dominates a second, that second program may well dominate the first from a targeting point of view, as revealed by a comparison of their $T D$ curves, or from an allocation point of view, as revealed by a comparison of their $A D$ curves. Although program reforms would usually be implemented on the basis of the comparison of their $P D$ curves, the information provided by the $T D$ and $A D$ curves enables detecting the effect of targeting and allocation rules on the overall performance of various programs.

For example, "bad" targeting may be intentional to gain middle class political support for a given program. In such a case, however, a progressive allocation mechanism among program participants may still make an extension of the program desirable. By contrast, a program may target a specific group whose members tend on average to be poor, but the allocation mechanism may be so much in favor of the richer members of that group that the program overall is not efficient in reducing poverty. Combining information on the overall as well as on the targeting and allocation impacts may thus be very useful to suggest reforms to improve program performance.

Analogously to what is done in Duclos et al. (2002), we also use the properties of the $P D$ curves to estimate the critical poverty line up to which a program reform can be considered to be poverty efficient at a given order of dominance. We further suggest how the taxation mechanisms implicit in the various programs, as well as their behavioral effects, may affect whether a program reform can be said to be poverty efficient or not.

We illustrate the methods with a comparison of two Mexican programs. The first is called PROCAMPO, a cash transfer for farmers designed to facilitate the transition to a rural market economy. The program was created in 1994 to offset the potentially negative impact of the termination of farming support programs (within the broader context of the liberalization of the Mexican agriculture agreed upon as part of the North American Free Trade 
Agreement). PROCAMPO transfers are given to eligible producers of basic crops on a per hectare basis. The program is due to be phased out in 2008 .

The second program is Liconsa (Leche Industrializada Conasupo). It provides milk subsidies for qualifying families. To qualify, families must earn less than two minimum wages and have children under the age of 12 . Comparing $T D$ curves reveals that PROCAMPO is better targeted than Liconsa. However, when allocation effects (the $A D$ curves) are taken into account, the resulting comparison of the $P D$ curves suggests that it would be poverty efficient to expand Liconsa and to reduce funding for PROCAMPO. This conclusion is nevertheless sensitive to differences in the behavioral impacts of the two programs. When likely differential behavioral impacts are taken into account, PROCAMPO becomes again the better program for efficient poverty reduction.

The rest of the paper proceeds as follows. Section 2 develops the analytical framework, Section 3 presents the empirical illustration, and Section 4 concludes.

\section{The framework}

\subsection{Program reforms}

For expositional simplicity, we assume that transfer programs simply add to individual incomes ${ }^{2}$. Poverty is assessed on the basis of the distribution of these individual incomes. An existing program $k$ transfers an average amount $t_{k}(y)$ per beneficiary of pre-reform income $y$, whose value is assumed to range from from 0 to $a$. The proportion of the population at income $y$ that benefits from the program is given by $\tau_{k}(y)$. Working in a continuous setting, let $F(y)$ be the cumulative density function of $y$, and let $f(y)$ be its derivative, the density of income at $y$. A "targeting function" can then be defined as

$$
\phi_{k}(y)=\tau_{k}(y) \cdot f(y) .
$$

$\Phi_{k}=\int_{0}^{a} \phi_{k}(y) d y \leq 1$ denotes the overall share of the population that benefits from the program. The cumulative distribution function $G_{k}(y)$ of benefit

\footnotetext{
${ }^{2}$ The framework could be easily extended to apply to any policy that affects well-being, directly or indirectly.
} 
recipients is given by

$$
G_{k}(y)=\frac{\int_{0}^{y} \phi_{k}(x) d x}{\Phi_{k}}
$$

and the density of recipients is then

$$
g_{k}(y)=\frac{d G_{k}(y)}{d y}=\frac{\phi_{k}(y)}{\Phi_{k}} .
$$

Program $k$ 's mean transfer across the population is given by

$$
T_{k}=\int_{0}^{a} t_{k}(y) \phi_{k}(y) d y
$$

although the average transfer among program $k$ 's beneficiaries equals

$$
\bar{t}_{k}=\frac{T_{k}}{\Phi_{k}}=\int_{0}^{a} t_{k}(y) g_{k}(y) d y .
$$

To identify poverty-efficient program reforms and to assess the targeting and allocation efficiency of alternative programs and program reforms, we will consider marginal increases in benefits that have the same relative distribution as the relative distribution of initial transfers, so that an agent at income $y$ who is already in receipt of a transfer $t_{k}(y)$ will see his net income increase by $t_{k}(y) d t_{k}$ following the reform. Those not already in receipt of the transfer will not be affected by this marginal reform. The impact of such a reform can then be decomposed into targeting and allocation components as follows:

$$
t_{k}(y) d t_{k}=\underbrace{\bar{t}_{k} d t_{k}}_{\text {Targeting }}+\underbrace{\left(t_{k}(y)-\bar{t}_{k}\right) d t_{k}}_{\text {Allocation }} .
$$

The reform $t_{k}(y) d t_{k}$ has the effect of keeping unchanged the relative distribution of benefits, since everyone's benefit is increased by the same proportion. The targeting component assigns the same absolute marginal benefit to all existing recipients. The allocation component adds marginally to benefits among recipients in proportion to the difference between existing individual and mean allocation.

To describe in greater details the distributive impact of these various components, note that a concentration index of benefits among recipients can be expressed as (see for instance Rao (1969))

$$
I_{k}=2 \cdot \int_{0}^{a} \frac{\bar{t}_{k}-t_{k}(y)}{\bar{t}_{k}}\left(1-G_{k}(y)\right) d G_{k}(y)
$$


Ceteris paribus, the lower the value of $I_{k}$, the more progressive (and the more "pro-poor") is the benefit $k$ - for a discussion, see Kakwani (1977) and Pfähler (1987) for instance.

Using (6) and (7), it follows that the proportional reform $t_{k}(y) d t_{k}$ has no impact on the program's concentration of benefits within its beneficiaries, since it increases $t_{k}(y)$ and $\bar{t}_{k}$ by the same proportion. The mean transfer increases, however, by $\bar{t}_{k} d t_{k}$.

The mean effect of the allocation component in (6) is nil, since

$$
\int_{0}^{a}\left(t_{k}(y)-\bar{t}_{k}\right) d t_{k} d F(y)=\left(\bar{t}_{k}-\bar{t}_{k}\right) \Phi_{k} d t_{k}=0 .
$$

The allocation component therefore involves a pure redistribution of benefits among recipients. It has the simple impact of spreading benefits away from their mean by a proportional factor $d t_{k}$. As can be checked from (7), this changes the concentration index by $I_{k} d t_{k}$. If the concentration index was negative initially (corresponding to a progressive benefit) it makes it even more progressive, and if it was regressive initially (corresponding to a positive concentration index), then the allocation effect increases its regressivity among benefit recipients.

As for the targeting component in (6), it changes mean transfers by $\bar{t}_{k} d t_{k}$. Being the same in absolute value for all beneficiaries, this targeting impact equalizes the distribution of transfers among recipients. As can be checked from (6) and (7), it changes $I_{k}$ by $-I_{k} d t_{k} /\left(1+d t_{k}\right)$, and thus moves the original concentration of benefits among recipients towards 0 . If the concentration index was negative (i.e,, progressive) initially among recipients, the targeting effect makes it less progressive, and if the benefit was regressive initially, the targeting effect makes it less so.

\subsection{Poverty impact}

Next, to assess the impact of a marginal program reform on poverty, we follow much of the literature and focus for simplicity on additive poverty indices. Let $P(z)$ be such an additive poverty index. It can be expressed as:

$$
P(z)=\int_{0}^{a} p(y, z) d F(y)
$$

where $z$ is the poverty line and $p(y, z)$ is the contribution to total poverty of an individual with income $y$. As in Duclos et al. (2002), we consider the 
class of poverty indices $P(z) \in \Pi^{s}(z)$ with

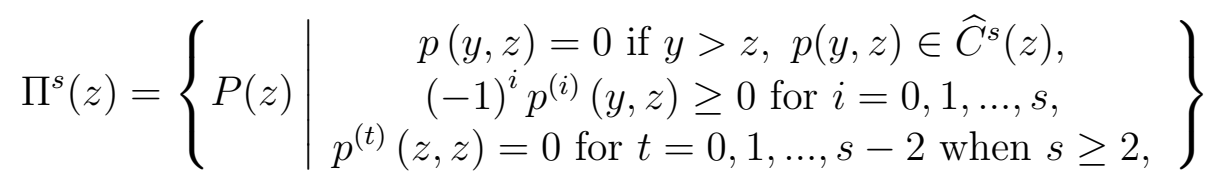

where $\widehat{C}^{s}(z)$ is the set of continuous functions which are $s$-time piecewise differentiable over $[0, z]$, and where the subscript ${ }^{(s)}$ stands for the $s^{\text {th }}$-order derivative with respect to $y$. The $\widehat{C}^{s}(z)$ continuity assumption is used for analytical simplicity. ${ }^{3}$

When $s=1$, poverty indices weakly decrease $\left(p^{(1)}(y, z) \leq 0\right)$ when an individual's income increases. These indices are thus "Paretian": increasing anyone's income cannot be bad for poverty. They are also symmetric: interchanging any two individuals' incomes leaves unchanged the poverty indices. Poverty indices within $\Pi^{2}(z)$ are also convex and must thus respect the Pigou-Dalton principle of transfers: a mean-preserving transfer of income from a higher-income person to a lower-income weakly decreases poverty. The $\Pi^{2}(z)$ indices are often said to be "distribution-sensitive" poverty indices. The poverty indices that belong to $\Pi^{3}(z)$ must also be sensitive to favorable composite transfers, namely, that a beneficial Pigou-Dalton transfer within the lower part of the distribution, accompanied by an adverse PigouDalton transfer within a higher part of the distribution, must weakly reduce poverty, provided that the variance of the distribution is not increased. The interpretation of higher-order classes of indices follows analogously ${ }^{4}$

A particular subclass of additive poverty indices is found in Foster, Greer and Thorbecke (1984). It is defined for $\alpha \geq 0$ by

$$
F G T_{F}^{\alpha}(z)=\int_{0}^{z}\left(\frac{z-y}{z}\right)^{\alpha} d F(y)
$$

$F G T^{0}(z)$ gives the most widely used index of poverty, the so-called poverty headcount, and $F G T^{1}(z)$ yields the (normalized) average poverty gap. Note that $F G T^{\alpha}(z)$ belongs to $\Pi^{s}(z)$ for $\alpha \geq s-1$.

\footnotetext{
${ }^{3}$ It could be relaxed to include indices whose $(s-1)^{t h}$ derivative is discontinuous and which are therefore not $s$-time piecewise differentiable. It would also be possible to include non-additive poverty indices (such as the Thon (1979) - Chakravarty(1983) Shorrocks(1995) poverty index) within a more general framework.

${ }^{4}$ For more details, see Duclos et al. (2002).
} 
The impact on the FGT indices of a marginal proportional increase of $d t_{k}$ in the resources allocated to program $k$ can be shown to be given by

$$
\frac{\partial F G T^{\alpha}(z)}{\partial t_{k}}=\left\{\begin{array}{cc}
-t_{k}(z) \phi_{k}(z) & \text { if } \alpha=0 \\
-\alpha z^{-\alpha} \int_{0}^{z} t_{k}(y)(z-y)^{\alpha-1} \phi_{k}(y) d y & \text { if } \alpha>0 .
\end{array}\right.
$$

This impact depends on the targeting function $\phi_{k}(y)$, on the allocation of transfers underneath $z$, and on the distribution of poverty gaps $z-y$.

The poverty impact in (12) can also be decomposed into a targeting and an allocation component. Using (6), the targeting component is given by

$$
\left.\frac{\partial F G T^{\alpha}(z)}{\partial t_{k}}\right|_{T}=\left\{\begin{array}{cc}
-\bar{t}_{k} \phi_{k}(z) & \text { if } \alpha=0 \\
-\alpha z^{-\alpha} \int_{0}^{z}(z-y)^{\alpha-1} \bar{t}_{k} \phi_{k}(y) d y & \text { if } \alpha>0 .
\end{array}\right.
$$

Note that (13) has a structure somewhat similar to $F G T^{\alpha-1}(z)$, as noted by Besley and Kanbur (1988) among others. The allocation component is given by

$$
\left.\frac{\partial F G T^{\alpha}(z)}{\partial t_{k}}\right|_{A}=\left\{\begin{array}{cc}
-\left(t_{k}(z)-\bar{t}_{k}\right) \phi_{k}(z) & \text { if } \alpha=0 \\
-\alpha z^{-\alpha} \int_{0}^{z}\left(t_{k}(y)-\bar{t}_{k}\right)(z-y)^{\alpha-1} \phi_{k}(y) d y & \text { if } \alpha>0 .
\end{array}\right.
$$

These distinctions allow comparisons of the impact of three types of program changes:

- the poverty impact of a "proportional" program change that increases all transfers by the same proportion, thus maintaining intact the relative distribution (and the concentration index) of transfers among existing recipients (equation (12));

- the poverty impact of a "lump-sum" program change that increases all transfers by the same absolute amount, maintaining unchanged the population of recipients (equation (13));

- and the poverty impact of an "allocative" program change that leaves unchanged the mean transfer that is distributed, but that increases by the same proportion $d t_{k}$ for all recipients their benefit's spread from that mean transfer, thus changing proportionately by $d t_{k}$ the transfer's concentration index among recipients (equation (14)). 


\subsection{Budgetary impact}

Now consider a marginal program reform that reduces marginally the resources devoted to program $l$ in order to increase marginally the resources allocated to program $k$. If the programs are funded through identical sources and if they do not induce behavioral reactions on the part of economic agents, then the cost to the government of increasing individual income on average by $1 \$$ is the same regardless of the program. However, programs may be funded through different means of taxation. They may also induce different behavioral responses on the part of their beneficiaries, especially (but not uniquely) if conditionalities are involved. In both cases, there can exist differential economic efficiency costs to raising individual incomes.

In order to take these factors into account, we need to evaluate the impact of marginal program reforms on the government budget. Let us denote by

$B$ this budget. The impact of a proposed program reform on the budget is given by

$$
d B=\frac{\partial B}{\partial t_{k}} d t_{k}+\frac{\partial B}{\partial t_{l}} d t_{l}
$$

Assuming budget neutrality, we have $d B=0$, and we may define an economic efficiency ratio $\gamma$ for additional expenditures on the two programs as

$$
\gamma=\frac{\left(\partial B / \partial t_{k}\right) / T_{k}}{\left(\partial B / \partial t_{l}\right) / T_{l}}
$$

The numerator in (16) gives the cost in government resources per dollar of increase in per capita income that is generated by reforming program $k$. The denominator gives the same indicator for a reform of program $l$.

The definition of $\gamma$ implicitly takes into account potential differences in the marginal cost of financing the two programs as well as potential differences in their behavioral impacts. If, for instance, running program $k$ is proportionately more costly administratively than running $l$, then $\gamma$ will exceed 1 . If the revenue source used for financing program $k$ is less economically efficient than that for financing program $l$ - because the deadweight loss and the economic distortions of using $k$ 's source of finance are larger - then again $\gamma$ will exceed 1. If program $l$ is better designed to induce benefit recipients to decrease less (or increase more) their labor supply or other income-generating activities, then program $l$ will be more efficient in generating increases in net income, and $\gamma$ will again exceed 1. 
For example, it will be argued in the empirical section that PROCAMPO, one of the two Mexican programs under review, may have multiplier effects, so that one peso in transfers can be expected to generate approximately an additional peso in revenues for beneficiaries. If Liconsa, the other program under consideration, does not have a similar behavioral impact, then abstracting from the issues related to the marginal cost of public funds, it could cost only half as much in budgetary terms to use PROCAMPO relative to Liconsa in order to increase individual incomes by one peso. In other words, PROCAMPO could be twice as economically efficient as Liconsa, and this would reflect itself in (16) in the derivatives of $B$ with respect to $d t_{k}$ and $d t_{l}$.

\subsection{Poverty-efficient program reforms}

Now, the ranking of the above program reforms may also well be contingent on the particular choice of a poverty line and of a poverty index. An important purpose of this paper is to identify program reforms that are poverty efficient - in the sense of necessarily decreasing poverty for all poverty indices $P(z) \in \Pi^{s}(z)$ and for all poverty lines up to some $z^{+}$. To do this, use (12) and define the program dominance curve for program $k$ as $P D_{k}^{s}(z)$ :

$$
\begin{aligned}
& P D_{k}^{s}(z)=-T_{k}-1 \frac{\partial F G T^{s-1}(z)}{\partial t_{k}} \\
= & \left\{\begin{array}{cc}
\frac{t_{k}(z)}{\bar{t}_{k}} g_{k}(z) & \text { if } s=1 \\
(s-1) z^{1-s} \int_{0}^{z}(z-y)^{s-2} \frac{t_{k}(y)}{\bar{t}_{k}} g_{k}(y) d y & \text { if } s>1 .
\end{array}\right.
\end{aligned}
$$

Note that $P D_{k}^{1}(z)$ is the density of public spending on program $k$ that is spent on individuals with income $z \cdot P D_{k}^{2}(z)$ gives the cumulative share of public spending on program $k$ that is spent on individuals with income $z$ or less ${ }^{5}$. As we will see in the illustration, this provides valuable descriptive information on the distribution of transfers. For $s \geq 3$, these shares are weighted by a power of the poverty gap which is increasing with $s$.

This leads to the following result (proofs appear in the appendix).

Proposition 1 A revenue-neutral marginal policy reform that increases proportionately all transfers under program $k$ and reduces proportionately all

\footnotetext{
${ }^{5}$ Assuming that, for expositional clarity, we normalize $P D_{k}^{2}(z)$ by $1 / z$. This, we do implicitly throughout the paper for all second-order dominance curves.
} 
those under program $l$ will reduce poverty for all poverty indices $P(z) \in \Pi^{s}(z)$ and for all poverty lines $z \in\left[0, z^{+}\right]$if and only if

$$
P D_{k}^{s}(y)-\gamma P D_{l}^{s}(y) \geq 0 \text { for all } y \in\left[0, z^{+}\right] \text {. }
$$

For $s=1$ and assuming $\gamma=1$, condition (19) means that the share of public spending on program $k$ that is directed to individuals with income $y$ must be higher than the share of the public spending on program $l$ directed to the same individuals, and this must be the case at every income level lower than $z^{+}$. For $s=2$ and $\gamma=1$, condition (19) implies that the cumulative share of spending on program $k$ that is directed to individuals with income $y$ or less must be higher than the corresponding cumulative share for program $l$, again for every income level lower than $z^{+}$. Whatever the ethical order of the classes of poverty indices, we need to assess whether the $P D$ curve for a program $k$ is higher than that for a program $l$, and this, at all income levels up to $z^{+}$. If this is so, it is poverty efficient to inject proportionately more resources into program $k$ at the expense of program $l$.

To assess the impact of a "lump-sum" marginal program reform, we use (13) and define a targeting dominance curve as:

$$
\begin{aligned}
& T D_{k}^{s}(z)=-\left.T_{k}^{-1} \frac{\partial F G T^{s-1}(z)}{\partial t_{k}}\right|_{T} \\
& =\left\{\begin{array}{cc}
g_{k}(z) & \text { if } s=1 \\
(s-1) z^{1-s} \int_{0}^{z}(z-y)^{s-2} g_{k}(y) d y & \text { if } s>1 .
\end{array}\right.
\end{aligned}
$$

$T D_{k}^{1}(z)$ represents the density of program beneficiaries at income $z$. $T D_{k}^{2}(z)$ shows the proportion of the population of beneficiaries who have income $z$ or less. For higher $s, T D_{k}^{s}(z)$ is simply a linear transformation of the $F G T_{G_{k}}^{s-2}(z)$ index (the index of those who benefit from the program $k$ ).

A program's targeting rule can be deemed good and will thus provide a good basis for a poverty-efficient lump-sum program reform

- if, for $s=1$, the program focuses on those who are just below the poverty line (large $g_{k}(z)$ in $(21)$ ),

- or if, for $s>1$, the program is such that $(z-y)^{s-2} g_{k}(y)$ in (21)) is large on average, viz, that the $F G T_{G_{k}}^{s-2}(z)$ index is large.

This leads to the following result. 
Proposition 2 A revenue-neutral "lump-sum" marginal policy reform that increases by the same amount the income of all recipients of program $k$ and decreases by the same amount the income of all recipients of program l will decrease poverty for all poverty indices $P(z) \in \Pi^{s}(z)$ and for all poverty lines $z \in\left[0, z^{+}\right]$if and only if

$$
T D_{k}^{s}(y)-\gamma T D_{l}^{s}(y) \geq 0 \text { for all } y \in\left[0, z^{+}\right] .
$$

We may also wish to determine whether a single program's revenueneutral allocative reform would be poverty efficient. For this, and using (14), define the following allocation dominance curve:

$$
\begin{aligned}
& A D_{k}^{s}(z)=-\left.T_{k}^{-1} \frac{\partial F G T^{s-1}(z)}{\partial t_{k}}\right|_{A} \\
& =\left\{\begin{array}{cc}
\frac{t_{k}(z)-\bar{t}_{k}}{t_{k}} g_{k}(z) & \text { if } s=1 \\
(s-1) z^{1-s} \int_{0}^{z} \frac{t_{k}(y)-\bar{t}_{k}}{\bar{t}_{k}}(z-y)^{s-2} g_{k}(y) d y & \text { if } s>1 .
\end{array}\right.
\end{aligned}
$$

Recall that an allocative reform increases by $I_{k} d t_{k}$ the concentration index $I_{k}$ of transfers. This reallocation of the benefits of a program $k$ will tend to be poverty efficient if those just below the poverty line receive currently more than their share of the benefit (for $s=1$ ) and would therefore benefit from a spread-increasing reform, or if there is a positive correlation between the spreads $\left(t_{k}(y)-\bar{t}_{k}\right)$ and the poverty contributions $(z-y)^{s-2} g_{k}(y)$ (for other values of $s)$.

Proposition 3 A marginal reform of program $k$ that increases proportionately the spread of all transfers from their mean value will decrease poverty for all poverty indices $P(z) \in \Pi^{s}(z)$ and for all poverty lines $z \in\left[0, z^{+}\right]$if and only if

$$
A D_{k}^{s}(y) \geq 0 \text { for all } y \in\left[0, z^{+}\right] .
$$

For any order of poverty dominance, $A D_{k}^{s}(y)$ is simply the difference between $P D_{k}^{s}(y)$ and $T D_{k}^{s}(y)$. $A D_{k}^{s}(y)$ may thus be interpreted as the gain (or the loss) in poverty reduction that is caused by existing allocation rules following a proportional program reform. The difference $A D_{k}^{s}(y)-A D_{l}^{s}(y)$ curves may therefore be understood as the difference that current allocation rules make to the assessment of a policy reform involving programs $k$ and $l$. Hence: 
Proposition 4 A revenue-neutral marginal policy reform that increases proportionately all transfers under program $k$ and reduces proportionately all transfers under program l will improve allocation for all poverty indices $P(z) \in$ $\Pi^{s}(z)$ and for all poverty lines $z \in\left[0, z^{+}\right]$if and only if

$$
A D_{k}^{s}(y)-\gamma A D_{l}^{s}(y) \geq 0 \text { for all } y \in\left[0, z^{+}\right] \text {. }
$$

\subsection{Bounds to poverty efficiency}

Whether one wishes to analyze overall program, targeting or allocation dominance, if the relevant dominance tests fail over an initial range of poverty lines $z \in\left[0, z^{+}\right]$, two different routes may be followed. One may increase the order of dominance until a robust assessment is obtained over the initially-specified range $\left[0, z^{+}\right]$. One may alternatively estimate an upper critical bound $z^{s}$ for a range $\left[0, z^{s}\right]$ of poverty lines that does not quite extend to $z^{+}$. The critical poverty lines $z_{P}^{s}, z_{T}^{s}, z_{A}^{s}$ and $z_{A R}^{s}$ beyond which conditions (19), (22), (25) and (26) do not hold anymore are given respectively by

$$
\begin{gathered}
z_{P}^{s}=\sup \left\{z: P D_{k}^{s}(y)-\gamma P D_{l}^{s}(y) \geq 0, \quad y \in[0, z]\right\} \\
z_{T}^{s}=\sup \left\{z: T D_{k}^{s}(y)-\gamma T D_{l}^{s}(y) \geq 0, \quad y \in[0, z]\right\} \\
z_{A}^{s}=\sup \left\{z: A D_{k}^{s}(y) \geq 0, \quad y \in[0, z]\right\},
\end{gathered}
$$

and

$$
z_{A R}^{s}=\sup \left\{z: A D_{k}^{s}(y)-\gamma A D_{l}^{s}(y) \geq 0, \quad y \in[0, z]\right\} .
$$

Estimators $\hat{z}^{s}$ of these critical values are given by replacing the population distribution with the sampling one. Their use will be illustrated in the next section.

\section{Empirical illustration}

\subsection{Mexican programs and data}

We now apply the above tools to an illustrative analysis of the impact of a balanced-budget reform involving two Mexican transfer programs. The 
first program, the "Program of Direct Payments to the Countryside" (PROCAMPO), is an income-support program for agricultural producers started in 1993/94. As noted by Cord and Wodon (2001), the program aims to ease the transition towards a market economy and specifically to facilitate the agricultural sector's adjustment to the removal of guaranteed prices and market support for key grains and oilseeds. It provides agricultural producers (those with the legal usufruct rights over the land) with a fixed payment per hectare that is not linked to current production trends. The number of eligible hectares per producer is the number of hectares the producer had devoted to the production of one of the nine PROCAMPO crops (maize, beans, wheat, cotton, soybeans, sorghum, rice, barley, safflower and barley) in one of the three agricultural cycles preceding August 1993. The payments are made per hectare for each crop season and, for greater transparency, are fixed at the same level across the country. PROCAMPO is a transitional program expected to terminate in 2008.

The second program is Liconsa (Leche Industrializada Conasupo). Qualifying families can purchase from 8 to 24 liters of milk per week at a discount of roughly 25 percent off the market price. To qualify, families must earn less than two minimum wages and have children under 12 . The ration of milk is determined by the number of children under the age of 12 ( 8 liters for families with one or two children, 12 liters for three children, and 24 liters for 4 children or more). About 5.1 million children benefit from such subsidies.

This illustration uses household level data from the 1997 ENCASEH survey conducted by the staff of PROGRESA, a large Government agency. The survey covers most areas of the countries and it has detailed information on program participation. Another survey which is more often used for work on poverty in Mexico is the ENIGH income and expenditures survey, which is conducted every two years. Unfortunately, the ENIGH does not have the information on program participation required here.

\subsection{First-order poverty efficiency}

Figure 1 provides estimates of the $P D^{1}(z), T D^{1}(z)$, and $A D^{1}(z)$ curves for different values of $z$. Per capita incomes on the horizontal axis have been normalized by regional poverty lines so that cost-of-living differences between urban and rural areas are taken into account. A value of one indicates that a household is at the level of the urban/rural poverty line used in a recent World Bank poverty assessment for Mexico. With these poverty lines, which 
are on the high side, 68.7 percent of the population is poor (those with per capita income below $z=1$ ).

The precise values of the $P D^{1}(z)$ and $T D^{1}(z)$ curves for $z=0.5, z=1$, and $z=2$ and their standard errors are given in Table 1 . The standard errors are based on the formulas derived in Duclos et al. (2002) and estimated using the $D A D$ software (Duclos, Araar and Fortin, 2001). The values of the $A D^{1}(z)$ curves for the various thresholds are not given in the table, but they can be readily obtained as the differences between the $P D^{1}(z)$ and $T D^{1}(z)$ curves. The two $P D^{1}(z)$ curves cross at $\widehat{z}_{P}^{1}=0.889$, with a standard error of 0.047 . Hence for any choice of poverty line $z$ below approximately $z=0.812$, if there were no differences in relative economic efficiency between the two programs $(\gamma=1)$, a policy maker could be confident (with a statistical confidence level of 95 percent) that increasing funding for a proportional increase in the generosity of Liconsa and reducing funding for a proportional decrease in the generosity of PROCAMPO would reduce poverty for all poverty indices belonging to $\Pi^{1}(z)$.

Recall that by (18) the $P D_{k}^{s}(z)$ curve gives directly the impact of a marginal proportional increase in program $k$ 's expenditures on the $F G T^{s-1}(z)$ poverty index - per peso of additional per capita expenditures (here expressed in units of the poverty line). $P D^{1}(z)$ thus provides immediately the impact of a program extension on the poverty headcount. Note that the point estimates of the two $P D^{1}(z=1)$ suggest that it would better to downsize Liconsa and enhance PROCAMPO to reduce the poverty headcount. This is clearly in conflict with the recommendation of the previous paragraph: it shows how the choice of poverty lines can matter for poverty and policy analysis. Note also, however, that the differences between the $P D^{1}(z)$ curves are not statistically significant beyond their crossing point at around $\hat{z}_{P}^{1}=0.89$.

While a $P D^{1}(z)$ curve gives the density of program benefits enjoyed by individuals with income $z$, the $T D^{1}(z)$ curves give the density of program beneficiaries at that same income. This useful descriptive information is again shown on Figure 1. The area underneath each of the density curves necessarily gives 1 . The two $T D^{1}(z)$ curves cross at $\widehat{z}_{T}^{1}=0.349$, with a standard error of 0.029 . For a range of poverty lines up to about $z=0.3$ a policy maker could be $95 \%$ certain that increasing funding for a lump-sum bonification of PROCAMPO, and reducing funding for a lump-sum decrease of Liconsa benefits, would be first-order poverty efficient and improve the performance of the two programs taken jointly. For poverty lines beyond about 0.4 , the opposite conclusion would hold. 
The difference between the $P D^{1}(z)$ and $T D^{1}(z)$ curves is shown on the figure by the $A D^{1}(z)$ curves. This is the difference between the density of program benefits and of program beneficiaries. Because there are very few differences in Liconsa per capita benefits by income level among Liconsa recipients (even though there are differences in total benefits, in proportion to the number of children below the age of 12 found in the household), the $P D^{1}(z)$ and $T D^{1}(z)$ curves are nearly identical, so that the $A D^{1}(z)$ curve takes a value close to zero throughout. For PROCAMPO however, and for low poverty lines, values of the $A D^{1}(z)$ curve are large and negative, suggesting a loss in benefits for the very poor in comparison to the share of benefits that they would have had if there had been no differences in benefits among program participants.

PROCAMPO thus gives a clear example of the role of the allocation mechanism among program participants with respect to the overall poverty impact of a program. While many PROCAMPO beneficiaries are poor farmers with small plots of land, some of the beneficiaries are fairly rich farmers with large landholdings, and thereby recipients of large PROCAMPO transfers since the transfers are proportional to the amount of land cultivated. Changing the allocation mechanism for PROCAMPO (that is, reducing its spread) would certainly improve the program's impact on extreme poverty in Mexico.

\subsection{Second-order poverty efficiency}

Some of the findings obtained for first-order poverty efficiency become stronger when we consider second-order poverty efficiency, that is, when we focus solely on "distribution-sensitive" poverty indices. These findings are shown on Figure 2 and Table 2. Recall that the $P D^{2}(z)$ and $T D^{2}(z)$ curves represent, respectively, the cumulative proportions (or cumulative densities) of program benefits and of program beneficiaries found in households with per capita income below a certain level. For example, the population below $z=0.5$ is estimated to account for 41.9 percent of Liconsa beneficiaries and 41.1 percent of Liconsa transfers. The same population includes 63.6 percent of the PROCAMPO beneficiaries and 28.1 percent of the PROCAMPO transfers.

We now observe that the targeting performance of PROCAMPO is unambiguously better than that of Liconsa over a large range of poverty lines, even though enhancing Liconsa and downsizing PROCAMPO is now second- 
order poverty efficient over a similarly large range of poverty lines - extending to well above $z=1$ - again, under the assumption that marginal economic efficiency is similar for the two programs. Note here a striking conflict between the policy conclusions drawn under alternative choices of poverty lines and poverty indices. Figure 1 suggested that it would be better proportionately to downsize Liconsa and expand PROCAMPO if the aim was to reduce the headcount index at $z=1$. Figure 2 reveals instead that it is better to invest additional resources in Liconsa at the expense of PROCAMPO for all distributive-sensitive poverty indices (this excludes the headcount, which does not obey the Pigou-Dalton transfer principle) and for any reasonable choice of poverty line.

The two $P D^{2}(z)$ curves still cross, but the crossing point is not shown on the graph since it takes place at $\widehat{z}_{P}^{2}=3.931$, with a standard error of 0.020 . That the ranking of these two $P D^{2}(z)$ curves is valid over a larger range of poverty lines than for $P D^{1}(z)$ follows from Lemma 1 in Davidson and Duclos (2000). Since the differences between the $P D^{2}(z)$ curves are statistically significant for a large range of $z$ values, a proportional policy reform involving the two programs would lead to a statistically significant reduction in the average poverty gap, for a wide selection of alternative poverty lines.

Importantly, therefore, while PROCAMPO is better targeted than Liconsa, Liconsa is the better program overall for proportional reforms of the program, viz, when the allocation of benefits among program participants is also taken into account. Clearly, judging from the $A D^{2}(z)$ curves of Figure 2, an allocative reform that decreased the spread of PROCAMPO benefits from the mean would be much more favorable to poverty alleviation than a similar allocative reform for Liconsa.

\subsection{The role of economic efficiency}

We have assumed so far that the economic efficiency of the two programs was the same - that is, that $\gamma=1$. While both programs are funded through general tax revenues (so that there is no difference in the marginal cost of public funds), the programs may have different behavioral implications. Research by Cord and Wodon (2001) and Sadoulet, de Janvry and Davis (1999) suggests that PROCAMPO may have multiplier effects, so that one peso in transfers generates one additional peso in revenues for program participants. Various hypotheses have been advanced to explain this multiplier effect. Thanks to cash availability and the lifting of liquidity constraints, or thanks to a reduc- 
tion in the risk faced by program beneficiaries, PROCAMPO may increase household investment and/or enable households to choose riskier investments with higher expected rates of return. PROCAMPO's transfers may also be large and concentrated enough to stimulate the local economy, raising the demand for local goods and services, thereby creating new income generating activities. Whatever the reason for PROCAMPO's multiplier effect, if such a multiplier effect exists for PROCAMPO but not for Liconsa, then the ranking of the two programs may be altered.

Return to Proposition 1. Assuming a multiplier of two for PROCAMPO would be equivalent for checking poverty efficiency to multiplying the program's $P D^{s}(z)$ curves by two (for all orders of poverty dominance). It can be shown in that case that the $P D^{s}(z)$ curves for PROCAMPO would always be above those of Liconsa, whatever the value of $s$ and of the income cut-off $z$. Hence, directing more resources towards PROCAMPO at the expense of Liconsa would clearly be deemed poverty reducing for any reasonable choice of poverty measures and poverty lines. Although this paper's objective is obviously not to settle definitely this issue of the relative economic and poverty efficiency of these two Mexican programs, the methodology proposed in it indicates clearly why and how such issues can matter for the assessment and the design of public policy.

\section{Conclusion}

This paper shows how simple graphical tools can be used to assess the poverty impact of different programs and program reforms. Program dominance curves are decomposed into the sum of a targeting dominance curve, which only takes into account who benefits from the program, and an allocation dominance curve, which reflects potentially large differences in allocations between program participants. Apart from generating substantial and useful descriptive evidence on the incidence of transfer programs, the use of these curves enables analysts to assess the poverty efficiency of program reforms without having to make strong assumptions on the exact value of poverty lines or on the nature of the poverty measures to be used. They also give valuable information to detect the differential effect of targeting and allocation rules and of economic efficiency on the overall performance of various programs and program reforms. 


\section{A Proof of propositions}

\section{A.1 Proof of proposition 1}

Suppose two income distributions $A$ (before a program reform) and $B$ (after a program reform). Duclos and Makdissi (2000) show that a necessary and sufficient condition for poverty to decrease when moving from $A$ to $B$, for all $P(z) \in \Pi^{s}(z)$, for all $z \in\left[0, z^{+}\right]$, and for any given $s \in\{1,2,3, \ldots\}$, is given by

$$
D_{A}^{s}(y) \geq D_{B}^{s}(y) \forall y \leq z^{+}
$$

where

$$
D_{A}^{s}(y)=\int_{0}^{y}(y-x)^{s-1} d F_{A}(x)
$$

Note that the continuity assumption $p^{(t)}(z, z)=0$ for all $t \in\{1,2, \ldots, s-2\}$ in 10 is important for ordering distributions at dominance orders 3 and higher. In the context of a marginal program reform, this necessary and sufficient condition naturally becomes

$$
d D^{s}(y) \leq 0 \forall y \leq z^{+} .
$$

We have that

$$
d D^{s}(y)=\frac{\partial D^{s}(y)}{\partial t_{k}} d t_{k}+\frac{\partial D^{s}(y)}{\partial t_{l}} d t_{l}
$$

Using revenue neutrality, (15) and (16), (34) may be rewritten as

$$
d D^{s}(y)=\left[\frac{\partial D^{s}(y)}{\partial t_{k}}-\gamma \frac{\bar{t}_{k}}{\bar{t}_{l}} \frac{\partial D^{s}(y)}{\partial t_{l}}\right] d t_{k}
$$

From equation (18), we obtain

$$
d D^{s}(y)=z^{s-1} T_{k}\left[-P D_{k}^{s}(y)+\gamma P D_{l}^{s}(y)\right] d t_{k} .
$$

Using (36), for $d t_{k}>0$ condition (33) is then equivalent to

$$
P D_{k}^{s}(y)-\gamma P D_{l}^{s}(y) \geq 0, \forall y \in\left[0, z^{+}\right] .
$$

\section{A.2 Proofs of propositions 2,3 and 4 .}

Considering the definitions (21) and (24) and the proof of proposition 1, the proofs of propositions 2,3 and 4 follow readily. 


\section{References}

[1] Atkinson, A.B. (1987), On the Measurement of Poverty, Econometrica, $55,759-764$.

[2] Baker, J.L. and Grosch, M.E. (1994), Poverty reduction through geographic targeting: How well does it work", World Development, 22, 983-995.

[3] Besley, T. and R. Kanbur (1988), Food Subsidies and Poverty Alleviation, The Economic Journal, 98, 701-719.

[4] Chakravarty, S.R. (1983), Ethically Flexible Measures of Poverty, Canadian Journal of Economics, 16, 74-85.

[5] Coady, D. and E. Skoufias (2001), On the targeting and redistributive efficiencies of alternative transfer instruments, mimeo, International Food Policy Research Institute, Washington DC.

[6] Cord, C., and Q. Wodon (2001), Do Mexico's agricultural programs alleviate poverty? Evidence from the ejido sector, Cuadernos de Economia, $114,239-256$.

[7] Cornia, G. A. and F. Stewart (1995), Two Errors of targeting, in Public Spending and the Poor: Theory and Evidence, ed. D. Van de Walle and K. Nead, John Hopkins University Press, Baltimore.

[8] Davidson, R. and J.Y. Duclos (2000), Statistical Inference for Stochastic Dominance and the for the Measurement of Poverty and Inequality, Econometrica, 68, 1435-1465.

[9] Duclos, J.Y., A. Araar and C. Fortin (2001), DAD: a software for Distributive Analysis / Analyse Distributive, MIMAP program, International Development Research Centre, Government of Canada and CRÉ FA, Université Laval (freely available at www.mimap.ecn.ulaval.ca).

[10] Duclos, J.Y., and P. Makdissi (2000), Restricted and Unrestricted Dominance for Welfare, Inequality and Poverty Orderings, Working paper 00-01, Department of Economics, Université Laval. 
[11] Duclos, J.Y., P. Makdissi and Q. Wodon (2002), Socially-Efficient Tax Reforms, Cahier de recherche 02-01, Département d'économique, Université de Sherbrooke.

[12] Foster, J., J. Greer and E. Thorbecke (1984), A Class of Decomposable Poverty Measures, Econometrica, 52, 761-776.

[13] Foster, J. and A.F. Shorrocks (1988a), Poverty Orderings, Econometrica, $56,173-177$.

[14] Foster, J.E. and A.F. Shorrocks (1988b), Poverty Orderings and Welfare Dominance, Social Choice and Welfare, 5, 179-198.

[15] Foster, J.E. and A.F. Shorrocks (1988c), Inequality and Poverty Orderings, European Economic Review, 32, 654-662.

[16] Grosch, M.E. (1995), Towards quantifying the trade-off: Administrative costs and incidence in targeted programs in Latin America, in Public Spending and the Poor: Theory and Evidence, ed. D. Van de Walle and K. Nead, John Hopkins University Press, Baltimore.

[17] Jenkins, S.P. and P.J. Lambert (1997), Three 'I's of Poverty Curves, With an Analysis of UK Poverty Trends, Oxford Economic Papers, 49, 317-327.

[18] Kakwani, N.C. (1977), Measurement of Tax Progressivity: An International Comparison, Economic Journal, 71-80.

[19] Makdissi, P. and Q. Wodon (2002), Consumption Dominance Curves: Testing for the Impact of Indirect Tax Reforms on Poverty, Economics Letters, 75, 227-235.

[20] Mayshar, J. and S. Yitzhaki (1995), Dalton Improving Tax Reform, American Economic Review, 85, 793-807.

[21] Pfähler, W. (1987), Redistributive Effects of Tax Progressivity: Evaluating a General Class of Aggregate Measures, Public Finance/ Finances Publiques, 42, 1-31.

[22] Rao, V.M. (1969), Two Decompositions of Concentration Ratio, Journal of the Royal Statistical Society, Series A, 132, 418-425. 
[23] Ravallion, M. and G. Datt (1995), Is Targeting Through a Work Requirement Efficient? Some Evidence for Rural India, in Public Spending and the Poor: Theory and Evidence, ed. D. Van de Walle and K. Nead, John Hopkins University Press, Baltimore.

[24] Sadoulet, E., A. de Janvry and B. Davis (1999), Cash Transfer Programs with Income Multipliers: PROCAMPO in Mexico, Mimeo, University of California at Berkeley.

[25] Shorrocks, A.F. (1995), Revisiting the Sen Poverty Index, Econometrica,63, 1225-1230.

[26] Skoufias, E. (2001), PROGRESA and its Impact on the Human Capital and Welfare of Households in Rural Mexico: A Synthesis of the Results of an Evaluation by IFPRI, International Food Policy Research Institute, Washington, DC.

[27] Slemrod, J., and S. Yitzhaki (1996), The Cost of Taxation and the Marginal Efficiency Cost of Fund, International Monetary Fund Staff Papers, 43, 172-98.

[28] Thon, D. (1979), On Measuring Poverty, Review of Income and Wealth, 25, 429 ? 439 .

[29] Wodon, Q. (1997), Targeting the poor using ROC curves, World Development, 25, 2083-2092.

[30] Wodon, Q., and S. Yitzhaki (2002), Evaluating the Impact of Government Programs on Social Welfare: The Role of Targeting and the Allocation Rules Among Program Beneficiaries, forthcoming in Public Finance Review.

[31] Zheng, B. (1999), On the Power of Poverty Orderings, Social Choice and Welfare, 3, 349-371.

[32] Zheng, B. (2000), Poverty Orderings, Journal of Economic Surveys, 14, 427-466. 
Figure 1: Procampo vs Liconsa, Dominance Curves, $s=1$

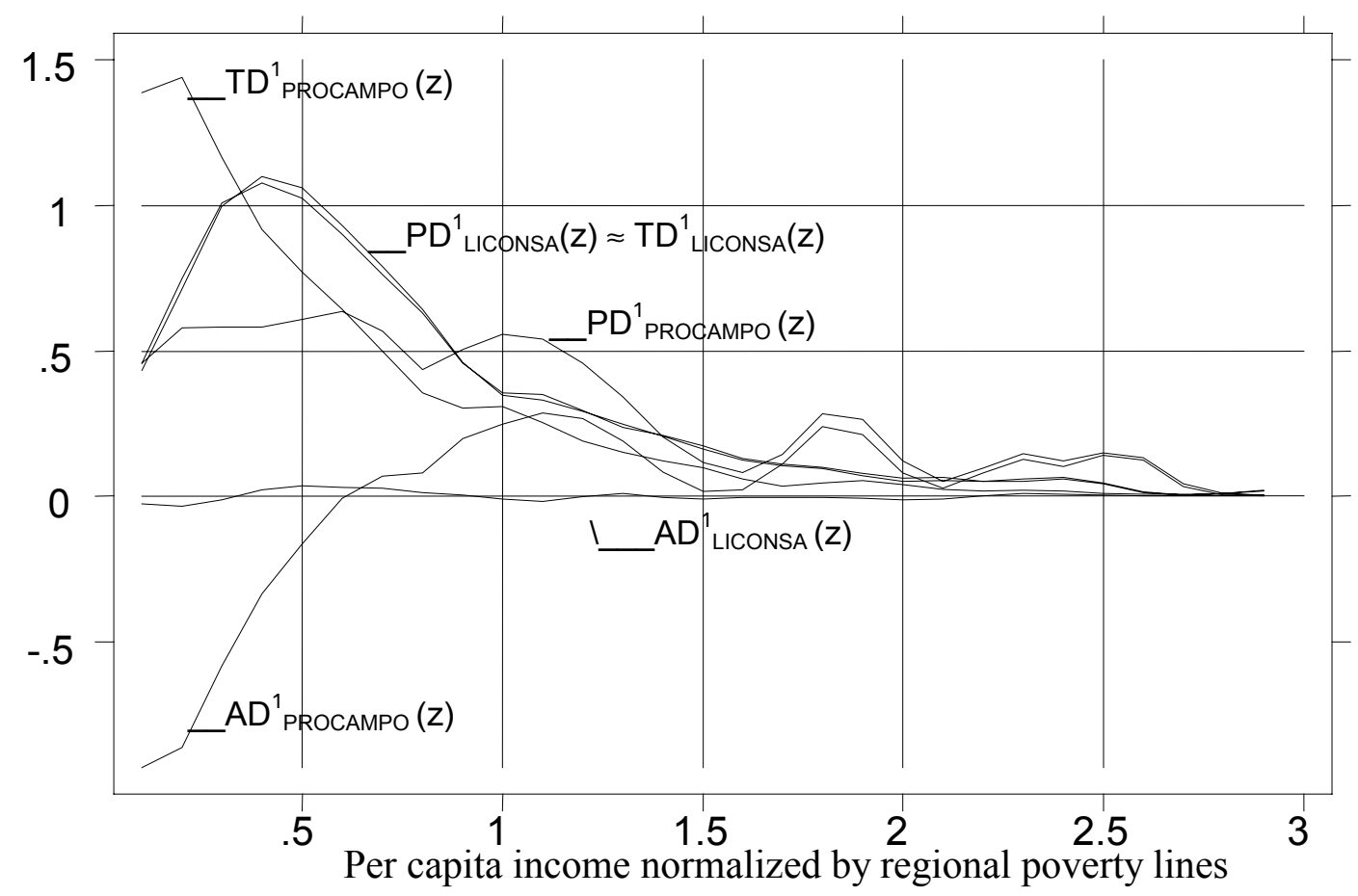

Figure 2: Procampo versus Liconsa, Dominance Curves, $\mathrm{s}=2$

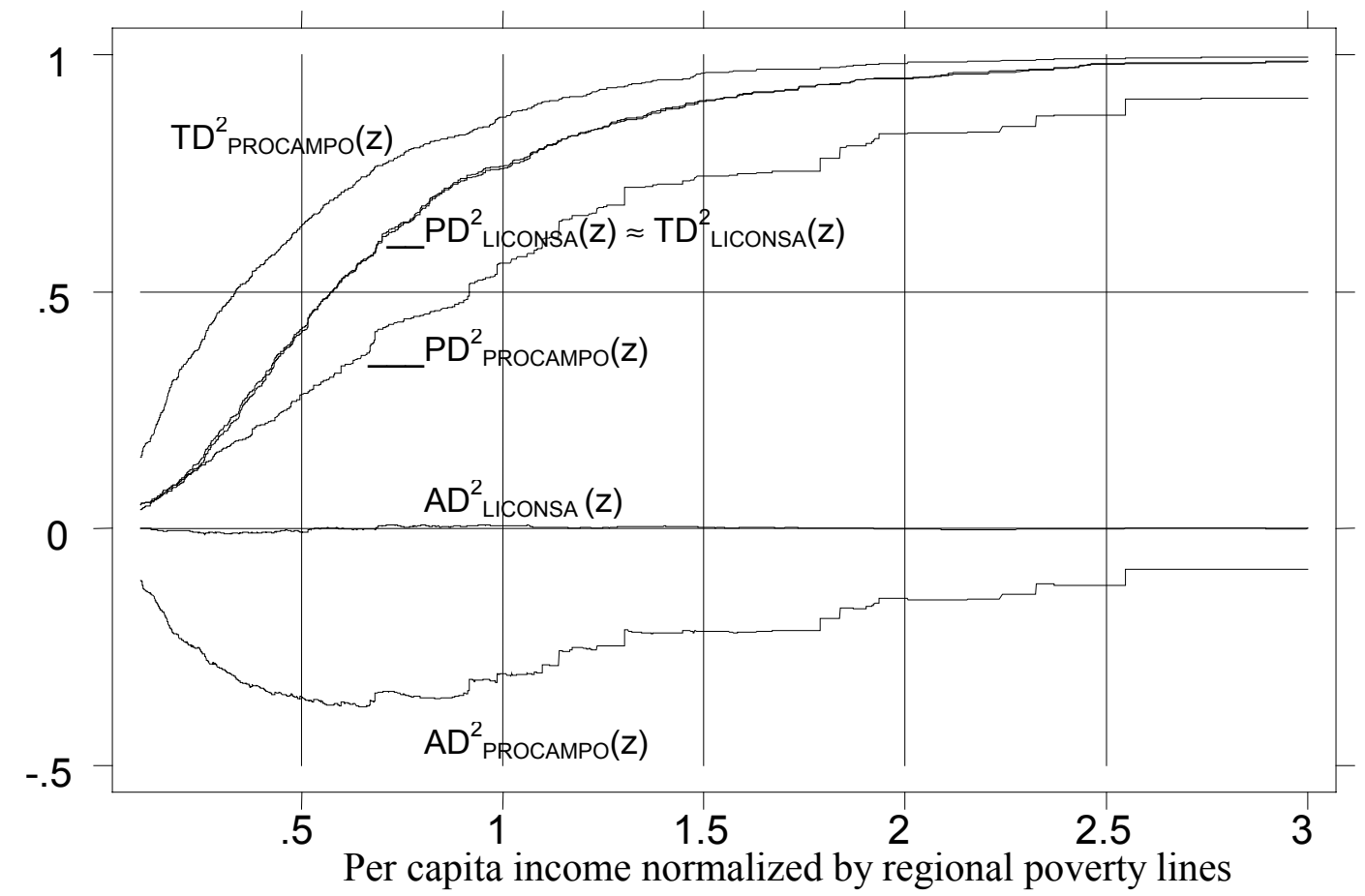

Source: Authors' estimation using 1997 ENCASEH. 
Table 1: Comparison of Procampo and Liconsa for s=1, Mexico 1997

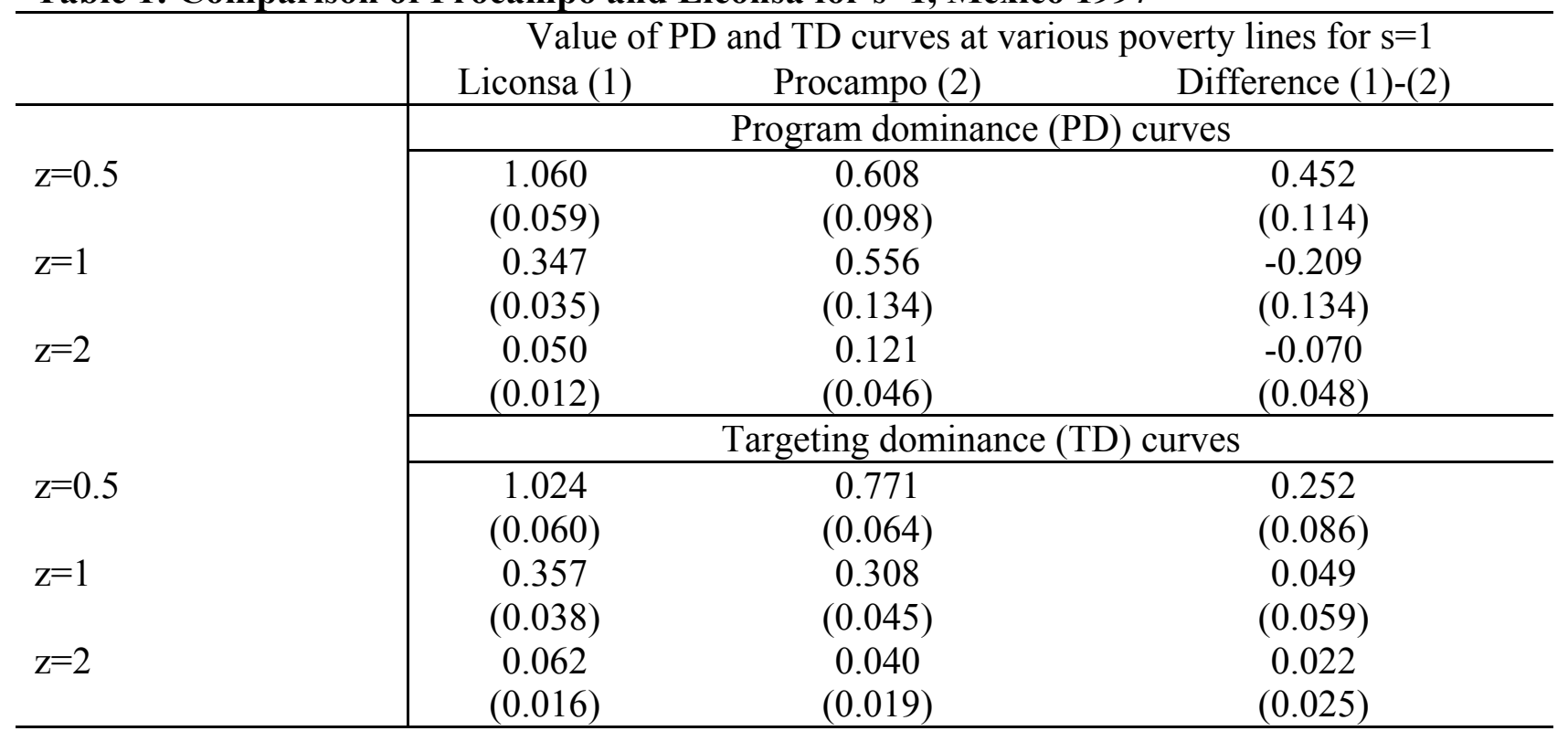

Source: Authors' estimation using 1997 ENCASEH. Sample size is 9911 observations. Incomes are normalized by regional poverty lines.

Table 2: Comparison of Procampo and Liconsa for s=2, Mexico 1997

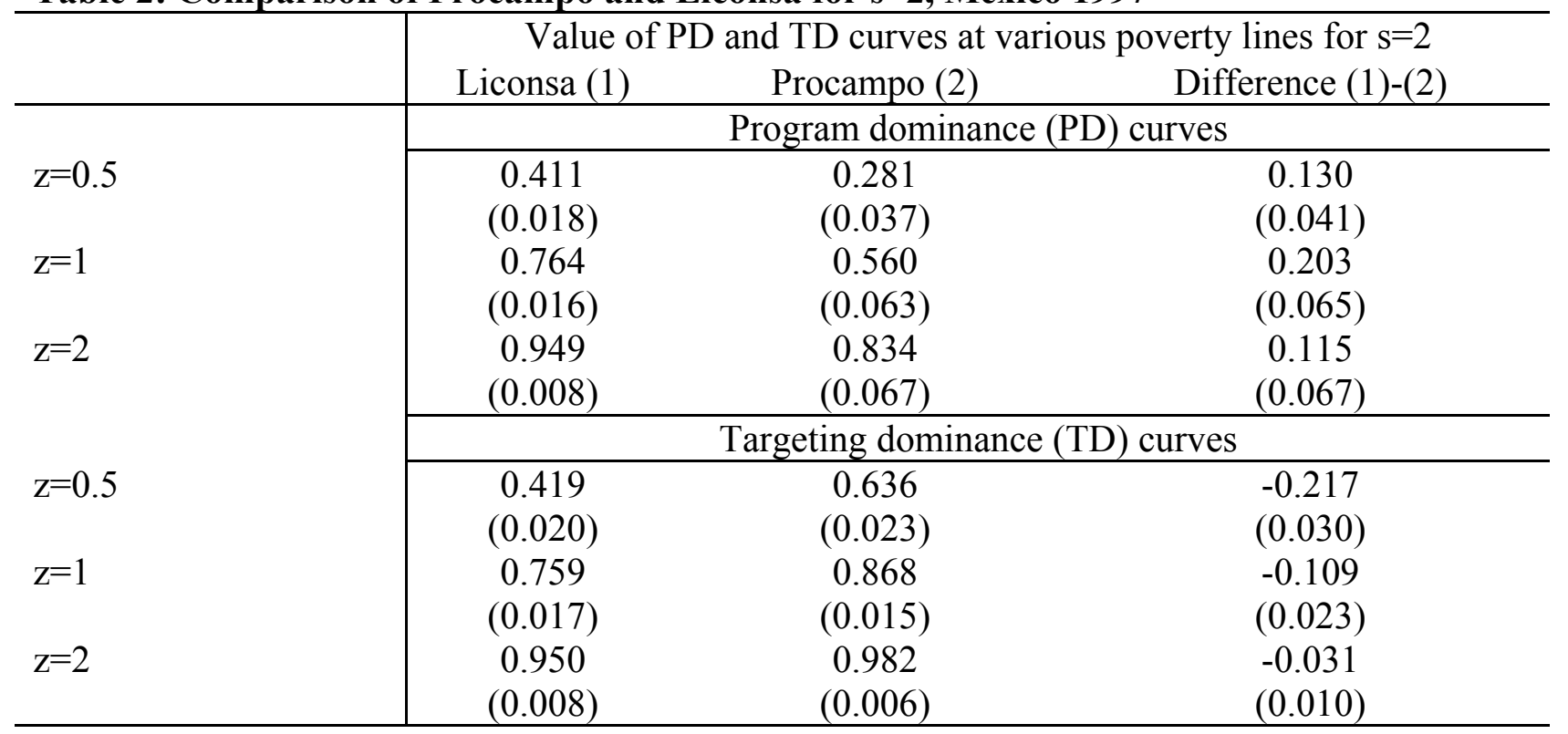

Source: Authors' estimation using 1997 ENCASEH. Sample size is 9911 observations. Incomes are normalized by regional poverty lines. 
94-01 BILO DEAU, Marc et AI SLIVINSKI, Toilet Cleaning and Department Chairing: Volunteering a Public Senvice.

94-02 ASCAH, Louis, Recent Retirement Income System Reform: Employer Plans, Public Plans and Tax Assisted Savings.

94-03 BILO DEAU, M. et AI SLIVIN SKI, Volunteering N onprofit Entrepreneurial Services.

94-04 HANEL, Petr, R\&D, Inter-Industry and International Spillovers of Technology and the Total Factor Productivity $G$ rowth of Manufacturing Industries in Canada, 1974-1989.

94-05 KALULUM IA, Pene et Denis BO LDUC, G eneralized Mixed Estimator for N onlinear Models: A Maximum Likelihood Approach.

95-01 FO RTIN, Mario et Patrice Langevin, L'efficacité du marché boursier face à la politique monétaire .

95-02 HANEL, Petr et Patrice Kayembe YATSHIBI, Analyse de la performance à exporter des industries manufacturières du Q uébec 1988.

95-03 HANEL, Petr, The C zech Republic: Evolution and Structure of Foreign Trade in Industrial G oods in the Transition Period, 1989-1994.

95-04 KALULUMIA, Pene et Bernard DÉCALUWÉ, Surévaluation, ajustement et compétitivité externe : le cas des pays membres de la zone franc CFA.

95-05 LATULIPPE, Jean-G uy, Accès aux marchés des pays en développement.

96-01 ST-PIERRE, Alain et Petr HANEL, Les effets directs et indirects de l'activité de R\&D sur la profitabilité de la firme.

96-02 KALULUM IA, Pene et Alain MBAYA LUKUSA, Impact of budget deficits and international capital flows on money demand: Evidence From Cointegration and Error-Correction Model.

96-03 KALULUMIA, Pene et Pierre YO URO UG OU, Money and Income Causality In Developing Economies: A Case Study 0 f Selected Countries In Sub-Saharan Africa.

96-04 PARENT, Daniel, Survol des contributions théoriques et empiriques liées au capital humain (A Survey of Theoretical and Empirical Contributions to Human Capital).

96-05 PARENT, Daniel, Matching Human Capital and the Covariance Structure of Earnings.

96-06 PARENT, Daniel, Wages and Mobility : The Impact of Employer-Provided Training

97-01 PARENT, Daniel, Industry-Specific Capital and the Wage Profile : Evidence From the N LSY and the PSID.

97-02 PARENT, Daniel, Methods of Pay and Eamings: A Longitudinal Analysis.

97-03 PARENT, Daniel, Job Characteristics and the Form of Compensation.

97-04 FO RTIN, Mario et Michel BERG ERO N, Jocelyn DUFO RT et Pene KALULUM IA, Measuring The Impact of Swaps on the Interest Rate Risk of Financial Intermediaries Using Accounting Data.

97-05 FO RTIN, Mario, André LECLERC et Claude THIVIERGE, Testing For Scale and Scope Effects in Cooperative Banks: The $C$ ase of Les $C$ aisses populaires et d'économie Desjardins.

97-06 HANEL, Petr, The Pros and Cons of Central and Eastem Europe Joining the EU

00-01 MAKDISSI, Paul et Jean-Yves DUCLOS, Restricted and Unrestricted Dominance Welfare, Inequality and Poverty 0 rderings 
00-02 HANEL, Petr, John BALDWIN et David SABO URIN, Les déterminants des activités d'innovation dans les entreprises de fabrication canadiennes : le rôle des droits de propriété intellectuelle

00-03 KALULUMIA, Pene, G overnment Debt, Interest Rates and International Capital Flows: Evidence From Cointegration

00-04 MAKDISSI, Paul et Cyril TÉJÉDO, Problèmes d'appariement et politique de l'emploi

00-05 MAKDISSI, Paul et Q uentin WO DO N, Consumption Dominance Curves: Testing for the Impact of Tax Reforms on Poverty.

00-06 FO RTIN, Mario etAndré LECLERC, Demographic Changes and Real Housing Prices in Canada.

00-07 HANEL, Petr et Sofiene ZORGATI, Technology Spillovers and Trade: Empirical Evidence for the G 7 Industrial Countries.

01-01 MAKDISSI, Paul et Q uentin WODON, Migration, poverty, and housing: welfare comparisons using sequential stochastic dominance. Avril 2001, 23 p.

01-02 HUNG Nguyen Manh et Paul MAKDISSI, Infantile mortality and fertility decisions in a stochastic environment Mars 2001, $12 \mathrm{p}$.

01-03 MAKDISSI, Paul et Q uentin WODON, Fuel poverty and access to electricity: comparing households when they differ in needs. Juin 2001, $19 \mathrm{p}$.

01-04 MAKDISSI, Paul et Yves G RO LEAU, $\mathbf{Q}$ ue pouvons-nous apprendre des profils de pauvreté canadiens ? Juillet2001, 47 p.

01-05 MAKDISSI, Paul et Q uentin WODON, Measuring poverty reduction and targeting performance under multiple govemment programs. Août 2001, 16 p.

01-06 DUCLO S, Jean-Yves et Paul MAKDISSI, Restricted inequality and relative poverty. Août 2001, $31 \mathrm{p}$.

01-07 TÉ ÉDO, Cyril et Michel TRUCHON, Serial cost sharing in multidimensional contexts. Septembre 2001, $37 \mathrm{p}$.

01-08 TÉJÉDO, Cyril, Strategic analysis of the serial cost sharing rule with symmetric cost function. Février 2001, 25 p.

01-09 HANEL, Petr, Current intellectual protection practices by manufacturing firms in Canada. Septembre 2001, $57 \mathrm{p}$.

02-01 DUCLO S, Jean-Yves, Paul M AKDISSI et Q uentin WO DO N, Socially-efficient tax reforms, Janvier 2002, $47 \mathrm{p}$.

02-02 MAKDISSI, Paul, La décroissance démographique : Pourquoi pas?, Février 2002, $20 \mathrm{p}$.

02-03 LEC LERC, André et Mario FO RTIN, Production et rationalisation des intermédiaires financiers : leçons à tirer de l'expérience des caisses populaires acadiennes, Février 2002, 24 p.

02-04 HANEL, Petr et Snezana VUCIC, L'impact économique des activités de recherche de I'Université de Sherbrooke, Février 2002, $44 \mathrm{p}$.

02-05 TÉjÉDO, Cyril et Michel TRUCHON, Monotonicity and bounds for cost shares under the path serial rule, Mars 2002, $18 \mathrm{p}$.

02-06 PO RET, Sylvaine et Cyril TÉjÉDO, Analyse horizontale du marché des biens illicites, Mai 2002, 15 p.

02-07 KALULUMIA, Pene, Effects of government debt on interest rates: evidence from causality tests in Johansentype models, Juillet 2002, $21 \mathrm{p}$.

02-08 MAKDISSI, Paul et $Q$ uentin WODON, C an safety nets offset the impact of risk on wage inequality and social welfare? Août 2002, 12 p. 
02-09 DUCLO S, Jean-Yves, Paul MAKDISSI et Q uentin WO DO N, Poverty-reducing tax reforms with heterogeneous agents, Février 2002, 10 p.

02-10 MAKDISSI, Paul et Q uentin WO DO N, Fuzzy targeting indices and orderings, Mai 2002, 11 p.

02-11 DUCLOS, Jean-Yves, Paul MAKDISSI et Quentin WODON, Poverty-efficient transfer programs : the role of targeting and allocation rules, Mai 2002, $25 \mathrm{p}$.

02-12 MAKDISSI, Paul et Q uentin WODON, Environmental regulation and economic growth under education externalities, Août 2002, $8 \mathrm{p}$.

* Tous ces cahiers de recherche sont disponibles sur notre site WEB (www.usherbrooke.ca/economique) ou au Centre de documentation de la FLSH A3-330 (UdeS).

Prière d'adresser vos commentaires ou demandes d'exemplaires d'un cahier de recherche antérieur (1976 à 1990) à monsieur Cyril TÉj ÉDO, coordonnateur des Cahiers de recherche du Département d'économique, Tél : 819) 821-7233 Télécopieur: 819) 821-7237 Courriel:

Cyril.Tejedo@ USherbrooke.ca

Comments or requests for copies of previous Working Papers (1976 to 1990) should be made to the Working Papers Coordinator at the Département d'économique, Mr. Cyril TÉDÉDO. Tel: (819) 821-7233 FAX:819) 821-7237 E-mail: Cyril.Tejedo@ USherbrooke.ca.

Révisé le 30-10-02 